\title{
CORRELATION OF TECTONICS, SEISMICITY AND GEOTHERMICS OF LESBOS ISLAND USING REMOTE SENSING DATA AND GEOGRAPHICAL INFORMATION SYSTEMS
}

\author{
N. Voulgaris, I. Parcharidis, M. Pahoula and E. Pirlis \\ Department of Geophysics-Geothermics, Faculty of Geology, University of Athens, PO Box 157- \\ 84,Panepistimioupoli - Zographou, Athens, voulgaris@geol.uoa.gr, parchar@geol.uoa.gr, \\ mpahoula@hotmail.com, ermispyrlis@hotmail.com
}

\begin{abstract}
The development of a specialized Geographical Information System aiming at the better understanding of the relation between tectonics, seismicity and geothermal potential of Lesbos Island is discussed in the present paper. The development of this system was based on the processing and analysis of satellite images in order to identify both tectonic and thermal anomalies for further correlation with available vector and raster data.

For this purpose a database including topology, geology, tectonics, seismicity and geothermy, was created. This data set derived from digitizing the topographic and geological maps of HAGS and IGME, from the analysis of the satellite image and from bibliography. As a result of the data processing there were indications about new evidence concerning the tectonics and the geothermy of Lesbos Island.
\end{abstract}

\section{INTRODUCTION}

The advantage of G.I.S. in comparison to other information systems is the ability to manipulate more complex information and spatial relations in short time. For this reason they comprise an important aid for geoscientists and they provide an immediate solution to problems that are associated with their field of interest.

The functionality offered by G.I.S. was the main advantage used in this study for the creation of a flexible, digital database. One of the main purposes for the creation of this database would be the investigation of the seismotectonic and geothermic regime of Lesbos Island. G.I.S. structure permits the evaluation of a possible correlation between these two parameters, in order to draw conclusions about the study area.

\section{GEOLOGY}

The geological structure of Lesbos Island consists of the following units: (1) the Autochthonous unit of Lesbos, (2) the Allochthonous units of Lesbos and (3) Post - Alpine formations. The Autochthonous unit consists of a series of formations of upper Paleozoic over upper Triassic, without stratigraphic unconformities. It consists of metaclastics, with lenses and interbedding of crystalline limestones and dolomites. It is characterized by a low metamorphic grade and does not consist of igneous rocks. The Allochthonous units overlaying the Autochthonous formations are separated in two tectonic nappes: a) In lower Triassic volcano - sedimentary formations and b) In lower ophiolithic rocks. The Post - Alpine formations consist of Neogene formations, lacustrine phases and Quaternary deposits (Migiros, 1992).

\section{TECTONICS}

Regarding tectonic evolution of Lesbos Island, this is affected by the general neotectonic evolution of the Aegean, which started during Oligocene (15 m.a.). Tectonic analysis of faults and micro- 
ruptures of Lesbos Island, performed by the IGME research team (Katsikatsos et al., 1982), results to the following conclusions:

a) In Lesbos Island there are three main fault systems with the following trends:

- $\mathrm{N} 40^{\circ}-60^{\circ} \mathrm{W}$

- $\mathrm{N} 30^{\circ}-60^{\circ} \mathrm{E}$

- $\mathrm{E}-\mathrm{W}$

b) The fault system of NE trend prevails at the NE part of the island.

c) Fault zones of NW and $E-W$ trends are parallel to the orientation of the coast.

d) Fault zones of $E-W$ trend are the oldest structures.

\section{SEISMICITY}

The neo-volcanic rocks of Lesbos have contributed to a high seismic activity. Foci of Lesbos Island are shallow ( $h \leq 50 \mathrm{~km}$ ) and concentrated in three zones. The first seismic zone crosses the north coast of Lesbos (magnitude of $6.0-7.0$ ). The second seismic zone crosses the south and southeastern coast of Lesbos Island (magnitude of $5.0-6.0$ ). The third seismic zone crosses the SW part of Lesbos with a NW orientation (magnitude $\leq 5.5$ ). This is the most active fault zone on Lesbos Island (Delibasis and Voulgaris, 1989).

\section{GEOTHERMY}

Lesbos Island exhibits a high geothermic interest and its geothermal fields are (Simeakis \& Someritis 1982, Fytikas 1986): Polihnitos: The size of this field is $10 \mathrm{~km}^{2}$, while fluid temperatures are $70-90^{\circ} \mathrm{C}$ with a mean temperature equal to $85^{\circ} \mathrm{C}$. Polihnitos - Lisbori: The size of this field is $12 \mathrm{~km}^{2}$. Geothermal fluids exhibit a very high content in $\mathrm{H}_{2} \mathrm{~S}$ and temperatures around $70-95^{\circ} \mathrm{C}$. Argenos: The size of this field is $5 \mathrm{~km}^{2}$, while fluid temperatures are $80-86^{\circ} \mathrm{C}$ with a mean temperature equal to $85^{\circ} \mathrm{C}$. Its $\mathrm{H}_{2} \mathrm{~S}$ content is lower than the one in Polihnitos. Stipsi-Kalloni: The size of this field is $20 \mathrm{~km}^{2}$ and fluid temperature is greater than $100^{\circ} \mathrm{C}$. The existence of a large number of springs is probably attributed to intense, recent shear tectonic activity, forcing underground water to rise rapidly towards the surface (Papastamatakis, 1972).

\section{METHODOLOGY AND DATA PROCESSING}

The methodology that was followed, includes the following steps:
1. Data Base Design.
2. Data acquisition.
3. Data input.
4. Processing - Analysis.
5. Correlations.
6. Evaluation.
7. Conclusions.

The primary data and the methodology used in this paper can be described as follows:

The topographic maps of Polihnitos, Plomari, Mithimna, Mitilini, Ayia Paraskevi and Eresos, on a scale of 1: 50,000 (HAGS, 1972). Moreover the geological maps of Plomari - Mitilini (ETHIGME previous name of IGME-, 1972), Ayia Paraskevi (ETHIGME, 1973), Polihnitos, Mithimna (ETHIGME, 1974) and Eresos (ETHIGME, 1975), on a scale of 1: 50,000. Topographic maps of HAGS were used for the creation of a DEM (contour interval $20 \mathrm{~m}$ ), from which spatial models, such as hillshade and aspect maps, were derived. The hillshade map was used for the identification and digitizing of probable faults, while the aspect map was used in order to locate the warmer areas, as a result of exposure to the sun at the time that the satellite image was acquired.

Lesbos Island seismological data originated from the following seismological catalogues: a) NEIC 1964 - 2000 (http://neic.usgs.gov/), b) Makropoulos et al. 1989, c) Papazachos \& Papazachou 1997, d) National Observatory of Athens $1964-2000$, e) Delibasis \& Voulgaris 1989. Emphasis was given to the seismological catalogue (e) derived from a local seismological network, 
selecting earthquakes with $\mathrm{RMS}<0.5, \mathrm{ERH}<10$ and $\mathrm{ERZ}<10$, while earthquakes with fixed depth at 5,10 and $20 \mathrm{~km}$ from the HYPO algorithm, were excluded.

The data concerning the existence of geothermal fields in Lesbos Island derived from papers or reports published by IGME or PPC (Papastamatakis 1972, Simeakis \& Someritis 1982, Minatidi et al. 1992) and are mainly related to the geothermal fields of Stipsi (NW Lesbos), Kaloni (central Lesbos), Argenos (east of Stipsi) and Polihnitos (south and central Lesbos).

The remote sensing data used are: A LANDSAT 5 TM satellite image (dated 20/08/1989, path: 181, row: 0.33 ), where the following major steps of a satellite image processing applied being: 1) restoration of the image and 2) image enhancement.

Image restoration consists of a wide spectrum of operations, including the geometric corrections. Correction of the image coordinates was based on the method of Ground Control Points (ERDAS IMAGINE 8.6). These points where recognized on the satellite image and were correlated with the respective points of a geographical orientated map, which depicts the particular area. Then a $3^{\text {rd }}$ degree transformation and the nearest point method were implemented, aiming to the resampling of the pixels of the satellite image (Sabins, 1997).

Image enhancement includes the following steps: A) Contrast Stretching. For the contrast stretching of the satellite image we used histogram correction techniques. At this particular study we implemented the simple linear method with $2 \%$ saturation point. B) Principal Components Analysis. Principal components analysis is an image transformation technique that aims to the conversion of highly related data to non - related data. Principal component analysis was applied to the 6 of the 7 images (except for the thermal band) and 6 components - images were derived. The component - image 1 was chosen for further process because it provides information concerning the topography of the area and that is because it is composed by the equal contribution of all the initial spectral bands. Therefore, component - image 1 doesn't have particular spectral information but it provides information about the topography. C) Filters. In order to increase the territorial frequency, high pass filters were implemented to some segments of the satellite image. Due to their ability to appoint boundaries between homogeneous pixel groups, filters were used for the edge enhancement. These boundaries could coincide with the hydrographic network of the area, the boundaries of different land use, different geological formations or tectonic structures (Sabins, 1997). Comparing the territorial enhancement of component - image 1 after the trial implementation of several high pass filters, it was concluded that only three of those filters were satisfyingly appointing the linear elements of the region without distorting the initial satellite image. The filters that were finally selected are: 1) A 3×3 Left Diagonal Edge, 2) A 3×3 Right Diagonal Edge and 3) A 5x5 Edge Enhance (ERDAS IMAGINE 8.6).

\section{COMMON POSSIBLE FAULT ZONES OBTAINED FROM THE SATELLITE IMAGE PROCESSING}

All possible fault structures of Lesbos Island, as they were obtained after processing component - image 1, since $3 \times 3$ Left Diagonal Edge, 3×3 Right Diagonal Edge and $5 \times 5$ Edge Enhance filters were implemented (ERDAS IMAGINE 8.6), are depicted in figure 1. Observations at the western part of the island show that NE - SW and NW - SE structures prevail. At the north and central part of the island the structures that prevail have an E - W and NNE - SSW trend. At the eastern part of the island, dominating structures have NE - SW trends, nevertheless structures crossing the above mentioned faults were observed. Finally, at the southeast part of the island all the above-mentioned structures are observed. It is important to notice that particular lineaments that are depicted on this image are digitized on more than one satellite images, which derived from filter implementations. As it was expected, possible fault structures with NW - SE trends were obtained from $3 \times 3$ Left Diagonal Edge filtering, while those with NE - SW trends were obtained from $3 \times 3$ Right Diagonal Edge and $5 \times 5$ Edge Enhance filtering. 


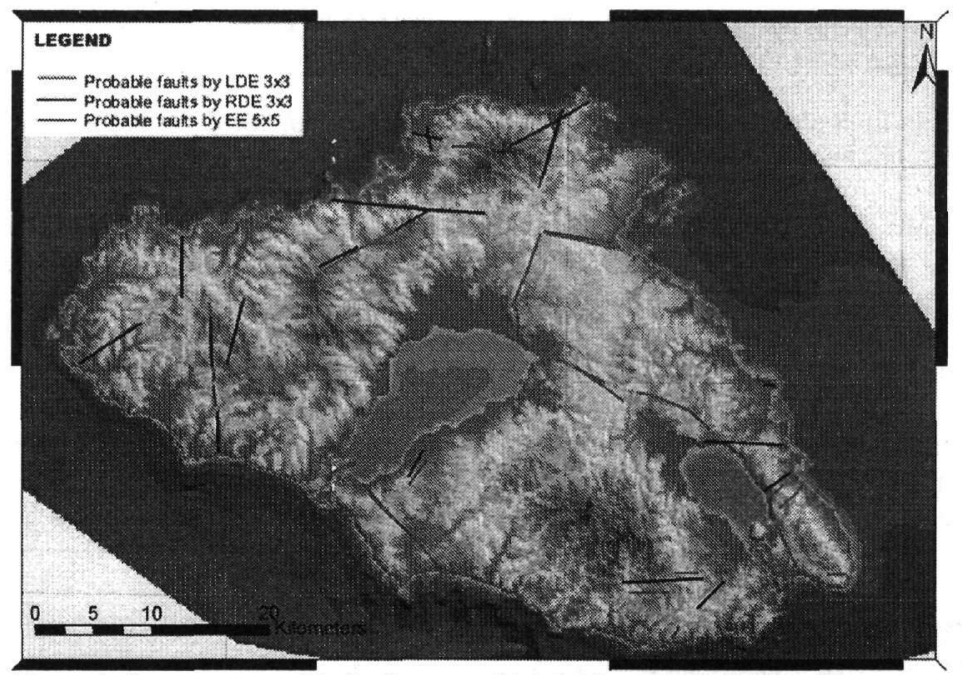

Figure 1. Common possible fault zones obtained from image processing.

\section{COMMON POSSIBLE FAULT ZONES OBTAINED FROM THE SATELLITE IMAGE PROCESSING AND HILLSHADE MAPS}

Two hillshade maps with $45^{\circ}$ and $315^{\circ}$ azimuth and solar elevation $45^{\circ}$ were used, besides satellite images, in order to map possible fault structures. The above azimuths were selected based on the available tectonic data (Katsikatsos et al., 1982) as well as a number of preliminary tests at various azimuths. Hillshade maps were created and projected on the grid of the area, for elevating and digitizing possible fault elements. Acquisition time of the satellite image is not the most suitable in order to recognize faults due to the high sun elevation. The problem is minimized due to the intense anaglyph of the island. Correlation of the fault structures that were obtained with the above processing was the next step. Figure 2 presents common fault structures that were obtained from satellite images and hillshade maps.

Fault structures with prevailing $\mathrm{N}-\mathrm{S}$ general trends are displayed in figure 2 . At the central and eastern part of Lesbos Island prevailing structures have $E-W$ trends, while NW - SE trends also appear.



Figure 2. Common possible fault zones obtained from satellite image processing and hillshade maps. 


\section{CORRELATION OF ETHIGME FAULTS WITH THE POSSIBLE FAULT ZONES OBTAINED FROM THE SATELLITE IMAGE PROCESSING AND HILLSHADE MAPS}

In the next step the possible fault structures, obtained as described above, were compared and correlated to the tectonic fabric of Lesbos Island as obtained from the geological maps of ETHIGME (Fig. 3).

A small number of ETHIGME faults coincide with those that were obtained from the hillshade maps and the satellite image, as displayed in figure 3. In general, the possible faults that coincide with the ETHIGME faults, have NW - SE and E - W trends, while at the southeastern part of the island faults with NNE - SSW trends are also observed. At the southwestern part of the island a possible fault, obtained from hillshade map (azimuth $315^{\circ}$ ), coincides with the south part of the island's great thrust.

The fact that a considerable number of possible faults does not coincide with any of the ETHIGME mapped faults, is partly justified by the geological regime, especially in areas covered by ignimbrites or by rocks affected by hydrothermal activity, since these formations do not provide insight on information related to linear elements, as they appear relatively smooth on satellite images.

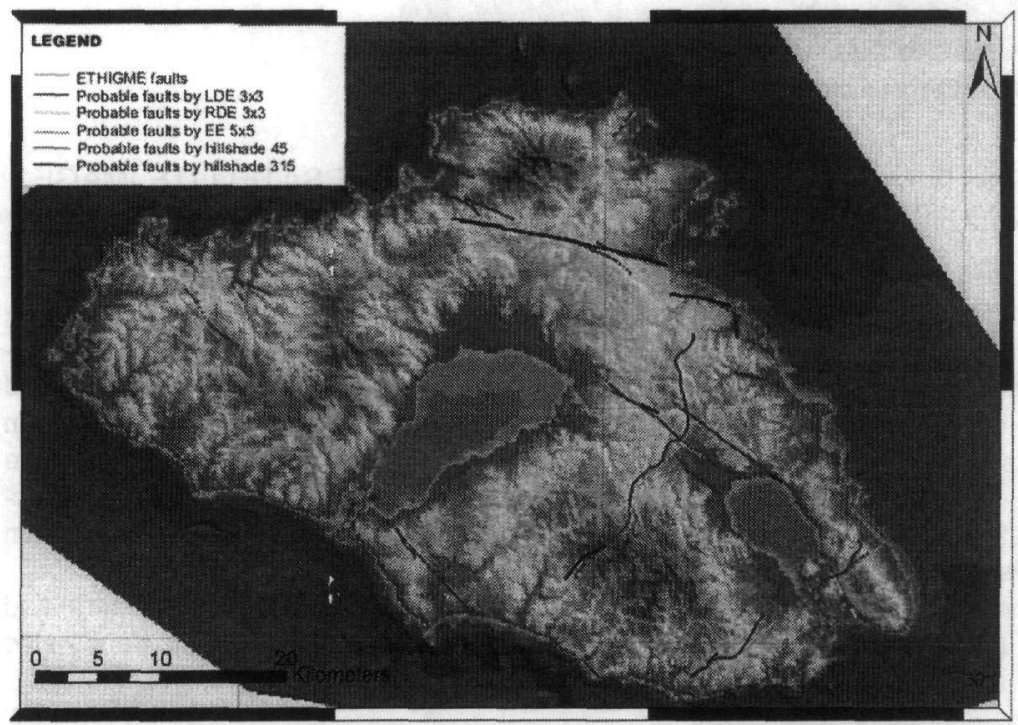

Figure 3. Correlation of ETHIGME faults and possible fault zones obtained from satellite image processing and hillshade maps.

\section{CORRELATION OF SEISMIC EPICENTERS WITH THE POSSIBLE FAULT ZONES OBTAINED FROM THE SATELLITE IMAGE PROCESSING AND HILLSHADE MAPS}

In order to verify the detection of the above mentioned possible faults, results which were obtained from satellite image processing and hillshade maps were correlated with seismological data from Lesbos Island. No prominent correlation can be observed between specific epicenter clusters and corresponding possible fault structures, which were obtained as described above. Nevertheless a significant concentration of fault structures is associated with a large number of seismic epicenters (Fig. 4). 


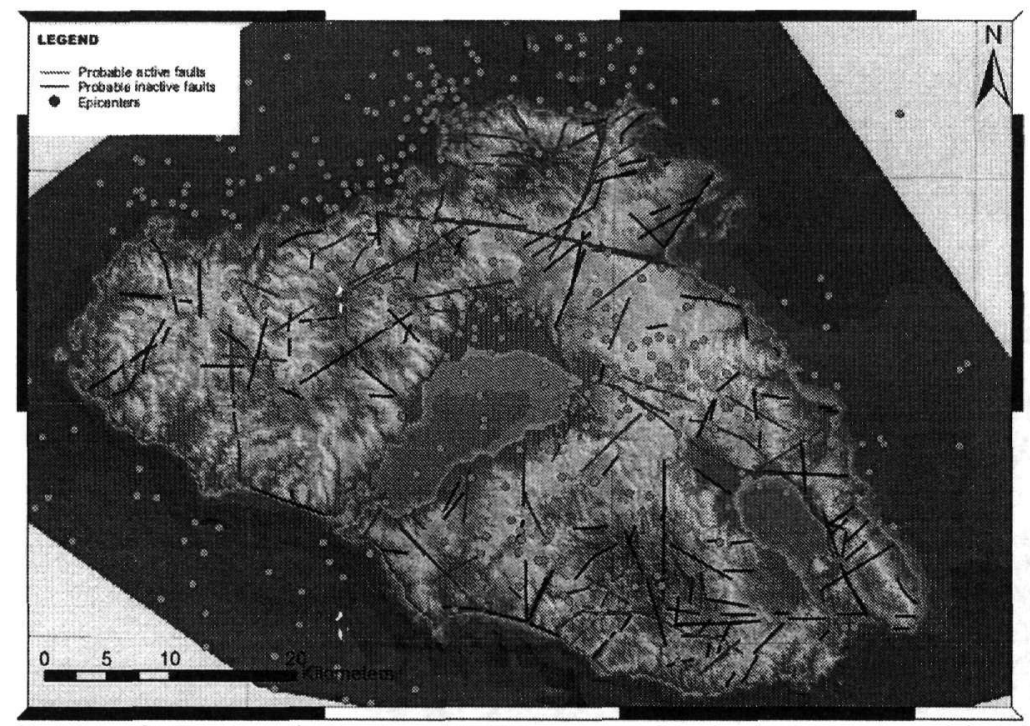

Figure 4. Correlation of seismic epicenters with possible fault zones obtained from satellite image processing and hillshade maps.

\section{CORRELATION OF HOT AND COLD SPRINGS WITH THE POSSIBLE FAULT ZONES OBTAINED FROM THE SATELLITE IMAGE PROCESSING AND HILLSHADE MAPS}

The association of surface manifestations of hot and cold springs with the existence of faults is evidenced by correlation between spring locations, as these are depicted on the geological and topographic maps of the area and possible fault structures, as these were obtained after the processing of the satellite image and the hillshade maps.

In order for the springs to be considered strong evidence of the existence of faults, they should be located on the surface manifestation of these faults. Yet, there are numerous springs that appear along the directions of the faults, but are located at their extension, a fact that could be attributed to inaccuracies either during the mapping of springs or during the digitizing of possible faults.

As it is shown in figure 5 , most possible fault structures derived from the hillshade maps or from satellite image, with small exception, fulfill the above requirements. This may not be regarded as immediate proof of the existence of these fault structures, however it is a strong indication, requiring further investigation. 


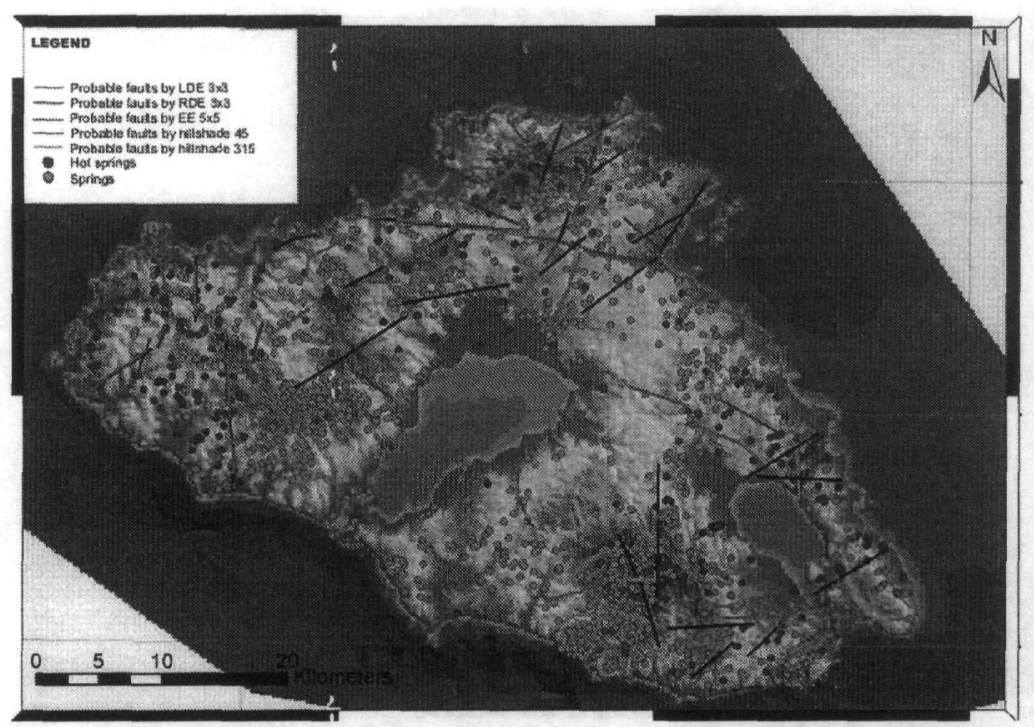

Figure 5. Correlation of springs with possible fault zones obtained from satellite image processing and hillshade maps.

\section{SEISMOTECTONICS AND GEOTHERMY}

Data and information that resulted from primary data processing, such as the thermogram (IDRISI 3.2), the tectonic fabric, hillshade maps, seismic epicenters, regions of sparse and dense vegetation (which were derived from the normalized differentiate index using the landsat data), hot springs (Geological maps of Greece, ETHIGME) and geothermal fields (Minatidi et al., 1992), were introduced into a Geographical Information System (ARCGis 8.0) in the form of layers and descriptive attribute tables, in order to correlate the seismotectonic regime of Lesbos Island with geothermy.

The geothermal field of Stipsi (1) is located at the northwest part of Lesbos. As shown on figure $6 a$, a significant number of faults cross this particular geothermal field. These faults derive from ETHIGME maps but also from the satellite image and the hillshade maps. The major fault zone with $E-W$ trend that crosses the central part of the Stipsi geothermal field, appears to be a significant feature in the sense that this structure is detected in all filtered satellite images and in both hillshade maps. Moreover it is very likely that this structure represents the western extension of one of the IGME mapped faults (Geological map of Greece, ETHIGME 1972). The rest of the possible fault structures that cross this geothermal field have $E-W$ and NNE - SSW trends.

The geothermal field of Kalloni (2) is located at the central part of the island (Fig. 6a). There are no faults depicted in this particular area in the maps of IGME. However there were a few structures obtained from the hillshade maps and the $5 \times 5$ Edge Enhance filtered satellite image. These fault structures have NW - SE and NNE - SSW trends respectively. Within the area of this field a number of epicenters is observed. These epicenters show a linear distribution parallel to the north and south boundaries of the field. Geothermic activity is expressed by the presence of hot springs.

The geothermal field of Argenos (3) is located east of the Stipsi geothermal field (Fig. 6a). This field is crossed by the extension of the above mentioned fault structure, with $E-W$ trend, that crosses the geothermal field of Stipsi. There are fault structures with NE - SW, NW - SE and NNE - SSW trends, obtained from the filtered satellite images and the hillshade maps.

The above three geothermal fields are located in areas of high seismic activity levels and a significant number of hot springs.

The geothermal field of Polihnitos (4) is located at the south, central part of the island (Fig. 6b). This field is crossed by faults with NW - SE trend, derived from the ETHIGME maps and the $3 \times 3$ Left Detection Edge and 3x3 Right Detection Edge filtered satellite images. These two filtered satellite images also show possible fault structures with NNE - SSW trend. In contrast to the three geo- 
thermal fields described previously, the Polihnitos field is characterized by limited seismic activity and lack of hot springs.

The thermogram of relative temperatures shows that the regions where the geothermal fields are located develop high relative temperatures as expected.

As far as these high temperature regions are concerned, some of them present a satisfying coincidence with the geothermal fields mentioned above, while some others show no coincidence with them.

More specifically polygon (A), shown on figure $6 \mathrm{a}$, represents an area of high relative temperatures that overlays a large part of the geothermal fields of Stipsi, Kalloni and Argenos, although some parts of this area do not coincide any of these fields. Hot springs are observed in the area nevertheless areas not covered by any of the geothermal fields receive a large amount of solar radiation and are characterized by limited vegetation. This could be a feasible explanation for high relative temperatures appearance.

Data concerning region of high relative temperatures $(B)$ are quite limited. As shown in figure 7 , there are no fault structures crossing the area. In addition, neither hot springs nor any seismic activity is observed. However, limited vegetation (Fig. 6a) favors high temperatures, despite the fact that exposure of this particular area to solar radiation appears to be limited.

Region (C) with high relative temperatures (Fig. 6 a) coincides with a region of geothermic interest called Mistegna. Despite the fact that there is no fault crossing this area according to ETHIGME maps, there is a possible fault obtained from the hillshade map (azimuth $45^{\circ}$ ), located at the western boundary of the area. The thermogram in figure 6 does not depict any hot water flowing towards the sea. The aspect map shows that high temperatures observed in the particular area do not result from solar radiation. It should also be mentioned that this particular field is characterized by limited vegetation and total absence of hot springs.

Region of high relative temperatures (D) overlaps a small area of the geothermal field of Polihnitos. In figure $6 \mathrm{~b}$ we observe that the southwest part of this area is crossed by possible faults with the same trend as the ones that cross the geothermal field of Polinnitos, while the north part of the area is crossed by possible faults with NE - SW and NNE - SSW trends. An interesting point is the fact that Agios loannis area, a geothermic interest region (Simeakis \& Someritis 1982), is contained within region (D). A significant part of this particular region is not exposed directly to solar radiation, as observed on the aspect map, therefore high relative temperatures may not be attributed to solar radiation.

Available information about the tectonic fabric of regions $(E)$ and $(F)$ (Fig. $6 b$ ) of high relative temperatures is insufficient due to the presence of alterated volcanic rocks. No correlation between seismic activity in the area and geothermic activity can be established because of the lack of information concerning the propagation of S-waves. Presence of hot springs suggests geothermic activity however these regions are characterized by limited vegetation and according to the aspect map are highly exposed to solar radiation.

At the northwestern part of Lesbos Island the thermogram indicates another area of high relative temperatures (G) (Fig. 6a). Nevertheless neither maps by ETHIGME, nor satellite images and hillshade maps provide any information about fault structures in the area. The slope aspect map shows that a significant part of the area is exposed to solar radiation, which, in combination to limited vegetation may account for high relative temperatures.

All previously mentioned areas are characterized by the presence of seismic epicenters, however epicenter concentration cannot be safely correlated with the geothermic potential of Lesbos island due to lack of information concerning S-waves propagation. 


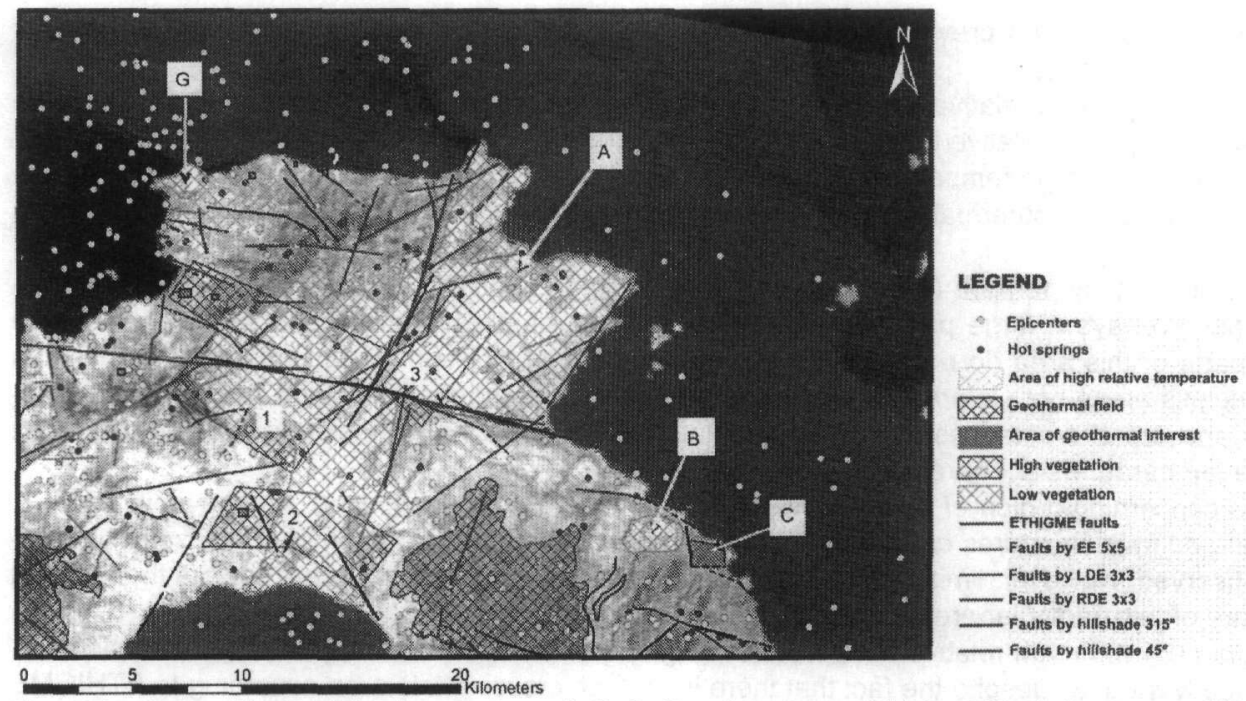

Figure 6a. Areas of high relative temperatures A, B, C, G and geothermal fields of Stipsi, Argenos and Kalloni.

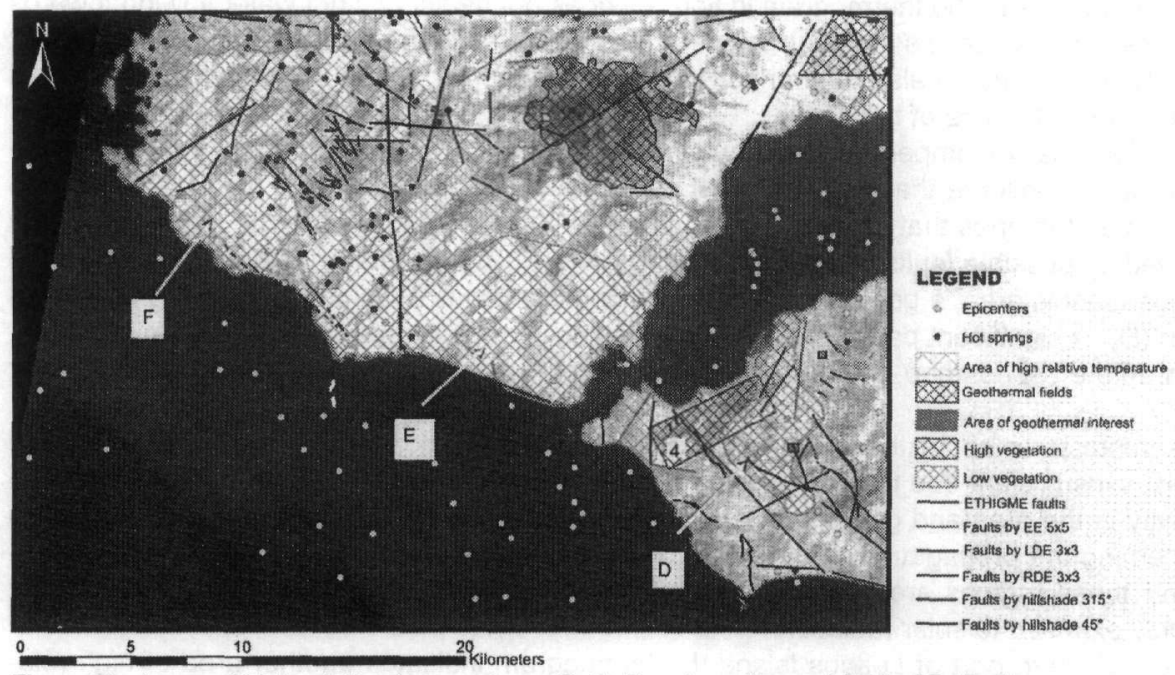

Figure $6 \mathrm{~b}$. Areas of high relative temperatures $D, E, F$ and geothermal field of Polihnitos.

\section{CONCLUSIONS}

The development of a Geographical Information System for the island of Lesbos provided better insight into the interaction between tectonics, seismicity and geothermal activity of the island.

Combined processing based on generated DEMs and satellite images resulted to the detection of probable faults characterized by $E-W, N E-S W$ and NW - SE trends which in many cases are parallel to the coastline, as referred by Katsikatsos et al. (1982).

As far as the seismicity of Lesbos is concerned, part of the epicenter distribution could be correlated to geothermal activity, as epicenter concentrations coincide with geothermal field areas. Nonetheless, further information, such as propagation properties of transverse seismic waves, would contribute to the correlation of seismicity and geothermal activity. Additionally, tectonic activity on Lesbos Island is also established by epicenter concentrations in areas of high fault density, which are not correlated to geothermal fields. 
Furthermore, the Geographical Information System provided a detailed visualization of geothermal activity in the investigated area. Data supporting this activity are the detection of high relative temperatures in the thermogram and the existence of hot springs. Secondary indications of geothermal activity can also be derived from detected faults and epicenters located in areas of low vegetation index.

Apart from the known geothermal fields, areas of possible geothermal interest were observed based on the high relative temperatures in the thermogram. Hot springs, faults and seismic epicenters are facts that confirm the above interpretation. In some cases the correlation of the thermogram's high temperatures to geothermal activity is uncertain and can be attributed to morphology and relative surface aspect in relation to sun exposure.

Uncertainties related to the above hypotheses can only be reduced or minimized by further research based on fieldwork observations, while additional data can be imported into the GIS database system continuously improving the effectiveness of the system.

\section{REFERENCES}

Delibasis, N.D., and Voulgaris, N.S., 1989. Microseismic and seismotectonic study of the island of Lesbos, Proceedings of the Fourth International Seminar on the Results of the EC Geothermal Energy Research and Demonstration, Florence, 27-30 April 1989, Kluwer Academic Publishers, 474-481.

ETHIGME, 1972. Geological map of Greece 1: 50,000, Sheet Plomari-Mitilini.

ETHIGME, 1973. Geological map of Greece 1: 50,000, Sheet Ayia Paraskevi.

ETHIGME, 1974. Geological map of Greece 1: 50,000, Sheet Mithimna

ETHIGME, 1974. Geological map of Greece 1: 50,000 , Sheet Polihnitos.

ETHIGME, 1975. Geological map of Greece 1: 50,000, Sheet Eresos.

Fytikas, M., 1986. Final conclusions regarding the geothermal research in Lesbos (on account of PPC), IGME (in Greek).

HAGS, 1972. Topographic map of Greece 1:50,000, Sheet Ayia Paraskevi.

HAGS, 1972. Topographic map of Greece 1:50,000, Sheet Eresos.

HAGS, 1972. Topographic map of Greece 1:50,000, Sheet Mithimna.

HAGS, 1972. Topographic map of Greece 1:50,000, Sheet Mitilini.

HAGS, 1972. Topographic map of Greece 1:50,000, Sheet Plomari.

HAGS, 1972. Topographic map of Greece 1:50,000, Sheet Polihnitos.

Katsikatsos, G., Mataragas, D., Migiros, G., and Triandafillou, E., 1982. Geological study of Lesbos island, Special Report, IGME.

Makropoulos, K.C., Drakopoulos, J., and Latoussakis, J., 1989. A revised earthquake catalogue since 1987, Geophys. J. Int., 98, 391-394.

Migiros, G.P., 1992: Introduction to the geology of Lesvos island, $5^{\text {th }}$ Meeting of IGCP Project 276. Chios - Lesvos. Athens Greece, May $25-31,1992$.

Minatidi, D.G., Pipili, I., and Kouri, D., 1992. Summary report on fieldtrip to Lesbos is/and in the framework of geothermal energy exploitation, IGME (in Greek).

Papazachos, B., and Papazachou, K., 1997. The earthquakes of Greece, Thessaloniki, Zitis Publications.

Papastamatakis, A., 1972. Hot springs of Polihnitos, Lesbos Island, IGME (in Greek).

SABINS F.F., 1997. Remote Sensing: Principles and Interpretation, W.H. Freeman and Company, p. 495, New York.

Simeakis, and Someritis, 1982. Geothermal research of Lesbos Island: Microtectonics - Neotectonics, IGME (in Greek). 